\title{
COMPARISON AND EVALUATION OF ANTIBIOTIC RESIDUES IN VARIOUS CHICKEN MEAT SAMPLES BY RP-HPLC METHOD
}

M. Naga Hanusha, Pingali. Sridevi ${ }^{\star}$, J. Kavitha, K. Vinutha, A. Mamatha and M. Bhagavan Raju

Department of Pharmaceutical Analysis, Sri Venkateshwara College of Pharmacy, Madhapur, Hyderabad-500 086, Telangana, India.

\begin{abstract}
Antibiotics can be used in chicken meat as growth promoters and also to increase poultry production, but the antibiotics usage in chicken meat results into a major risk for humans dueto antibiotic resistance. In the present study ten chicken meat samples were collected from different regions of Hyderabad. Liquid-liquid extraction process was used for the extraction of Sulphamethoxazole, Acetonitrile, Acetone and Dichloromethane were used asorganic solvents. Microbiological method and was done for the determination of Sulphonamides in chicken meat samples. Thin layer chromatography was done to determine sulphamethaoxazole and other sulphonamides using Dichloromethanemethanol-water in the ratio of 69:35:6 as mobile phase. Retention factor (Rf) was calculated after chromatograms detected by spraying the plate with Fluorescamineand observed under Ultraviolet chamber. Quantification was done using RP-HPLCusing KROMOSIL 100 C18Column, $5 \mu$, Mobile phase: di sodium hydrogen phosphate:methanol (75:25), Flow rate: $1 \mathrm{ml} / \mathrm{min}$, Pump mode: isocratic, Run time: 10min, Column temperature: $25^{\circ} \mathrm{CInjection}$ volume: $20 \mu \mathrm{l}$, Detection: UV at $266 \mathrm{~nm}$.Out of ten areas selected in Hyderabad region it was found that sulphonamide(sulphamethoxazole) concentration was more in Yakutpura and Mehdipatnam areas which are above MRLs $(0.1 \mu \mathrm{g} / \mathrm{ml})$ (Maximum Residue Limit (MRL)recommended limit according to the European Union (EC). All the results showed that the developed method was accurate, simple and can used for the laboratory purpose for theanalysis of antibiotic residues in chicken meat.
\end{abstract}

Keywords: Antibiotics, Chicken meat, poultry and sulphamethoxazole.

\section{INTRODUCTION}

Poultry industry is one of the biggest industries in India and globally in terms of production it is ranked 17th position. Accidentally, it was found that by- products of antibiotic production (dried streptomyces aureofaciens broth) which contain a high level of vitamin B12, when feed to poultry animals resulted in higher growth. Eventually, it was discovered that the trace amount of antibiotics remaining in these byproducts accounted for high growth. Since then the antibiotics have been used on poultry in large quantities to enhance production in poultry. However, the use of antibiotics in food animals poses a major risk for humans due to antibiotic resistance.

Antibiotic use is related to emergence of resistant bacteria in the animal which later transmits to human through food, environment and direct contact with the affected meat. Residues of antimicrobials compounds are also found in foods of animal 's origin as a 
result of inappropriate or excessive usage of these compounds. These residues are also known to transfer to humans through food and environment. To prevent any residues of antibiotics in food and food products of animal origin, withdrawal periods are set by regulatory agencies.

Withdrawal period is a time between the last dose of antibiotic given to food animals and consumption of food animals or food derived from it. It needs to be mentioned on the antibiotics that are used for animals. Antibiotics in poultry farming can be used as therapeutic agents, Prophylactic agents, growthpromoters.

Literature survey revealed that various analytical methods reported for the estimation of antibiotic residues. No method was developed for the estimation of antibiotic residues in various chicken meat samples in the area of Hyderabad by RP-HPLC. Hence RP-HPLC method can be developed for the estimation of antibiotic residues in various chicken meat samples from Hyderabad.

In the present study an attempt is made to know the concentrations of antibiotic residues in different areas by chromatographic techniques.

\section{MATERIALS AND METHODS Sample collection}

For determination of sulfonamide concentration, ten meat samples were collected from five different zonal areas of Hyderabad. Like Secundrabad in east side, YakutPura in west side, Mehdipatnam in north side, Amberpet in south side and khairthabad in center, these samples were taken and analyzed.

\section{INSTRUMENTS}

Weighing machine of SARTORIUS, Incubator of CINTEX, Autoclave, Hot air oven of SISCO, UV chamber of SECOR, HPLC of YOUNG YL Instrument using UV detector, Sonicator of LALCO Scientific Instruments, Centrifuge of REMI.

\section{CHEMICALS}

$\checkmark$ Different antibiotics like Sulphamethoxazole and sulphamethazine were obtained from yellow Chem product.

$\checkmark$ Methanol, Acetonitrile of analytical grade and Glacial Acetic Acid were obtained from MERCK laboratories.

$\checkmark$ Water of HPLC grade from Milli-Q, diNatrium Hydrogen Phosphate.

\section{Determination of Antibiotic Residues} Microbiological assay for the determination of Suphonamides using Agar Plate Method Take the sterile nutrient agar tubes, at 40$45^{\circ} \mathrm{C}$ transfer a loop of culture of $24 \mathrm{hrs}$ old Bacillus subtilis and mix thoroughly. Pour the solution into sterile Petri plates under aseptic conditions. Allow the plates to solidify, after complete solidification, make the wells using sterile borer and label the cups. Fill the cups using disposable syringe with the respective dilution. Do not disturb the plates after addition of antibiotic solution and let the solution diffuse. Then place all the plates in the incubator at $37^{\circ} \mathrm{C}$ for $24 \mathrm{hrs}$. After $24 \mathrm{hrs}$, measure the diameter of zone of inhibition.

Thin Layer Chromatographic method for the determination of Sulphonamides

TLC Conditions

$\checkmark$ TLC plates: Plate coated with silica gel

$\checkmark$ Mobile phase: ethyl acetate: n-butanol: methanol: aqueous ammonia $(35: 45: 15: 2 \mathrm{v} / \mathrm{v} / \mathrm{v} / \mathrm{v})$

$\checkmark$ Spraying reagent: fluorescamine

$\checkmark$ Detection: ultraviolet light

\section{Preparation of TLC plate}

TLC $20 \times 10$ plate coated $0.25 \mathrm{~mm}$ thickness with silica gel were used for the determination of Sulphamethaxazole in chicken sample.

Preparation of mobile phase:

Mobile phase was prepared by mixing of ethyl acetate, n-butanol, methanol and aqueous ammonia in the ratio of 35:45:15:2 v/v/v/v

\section{Preparation of Standard Solution}

Standard solution of Sulphamethaxazole and Sulphamethazine was prepared by dissolving $0.05 \mathrm{~g}$ of Sulphamethaxazole and Sulphamethazine powder in $100 \mathrm{ml}$ of mobile phase each.

\section{Sample preparation}

A volume of $30 \mathrm{ml}$ acetonitrile was added to 10 $\mathrm{g}$ of minced and homogenized muscle tissue weighed in a glass centrifuge tube. The sample was homogenized for $1 \mathrm{~min}$ in a vortex and centrifuged at $3500 \mathrm{rpm}$ for $10 \mathrm{~min}$. Then the supernatant was transferred into a pearshaped flask, add $20 \mathrm{ml}$ of acetone to the sediment before the mixture was sonicated for $10 \mathrm{~min}$. The solution was centrifuged once again and the supernatant was added to same pear-shaped flask. The mixed solution was evaporated $40^{\circ} \mathrm{C}$ until near dryness. Afterwards, $5 \mathrm{ml}$ of dichloromethane was added, homogenized by vortexing and transferred into a test tube. The step of addition of dichloromethane was repeated three times and the combined 
dichloromethane was dried at $40^{\circ} \mathrm{C}$. The residue was reconstituted with $1 \mathrm{ml}$ of $50 \%$ methanol in di-natrium hydrogen phosphate solution $(6 \mathrm{~g} / 1000 \mathrm{ml})$ and mixed properly by vortexing. $\mathrm{N}$-hexane $(2 \mathrm{ml})$ was added into the test tube for defeating and vortexing before being removed.10 $\mu \mathrm{l}$ of standard and sample solutions were placed on TLC plate. Treated plate were transferred to TLC tank containing mobile phase. After reaching the solvent front to end of plates, chromatograms detected by spraying the plate with a fluorescamine and observed under ultraviolet light.

RP-HPLC Method for the determination of Sulphamethaxazole

Preparation of di sodium hydrogen phosphate

Weigh $6 \mathrm{~g}$ of di sodium hydrogen phosphate in $1000 \mathrm{ml}$ volumetric flask and make up the volume with distilled water.

\section{Preparation of mobile phase}

Prepared a required volume of degassed mixture of di sodium hydrogen phosphate and methanol in the ratio of 75:25 v/v.

\section{Preparation of standard solution}

Weighed and transferred $100 \mathrm{mg}$ of sulphamethaxazole working standard into a100ml clean, dry volumetric flask. Make up the volume with mobile phase $(1000 \mu \mathrm{g} / \mathrm{ml})$. Diluted $1 \mathrm{ml}$ standard stock solution to a $100 \mathrm{ml}$ volumetric flask with mobile phase as diluents and mixed well $(10 \mu \mathrm{g} / \mathrm{ml})$. Further the solution is diluted to get $0.2,0.4,0.6,0.8,1,1.2 \mu \mathrm{g} / \mathrm{ml}$ concentrations respectively.

\section{Preparation of sample solution (Liquid- liquid extraction method)}

A volume of $30 \mathrm{ml}$ acetonitrile was added to 10 $\mathrm{g}$ of minced and homogenized muscle tissue weighed in a glass centrifuge tube. The sample was homogenized for $1 \mathrm{~min}$ in a vortex and centrifuged at $3500 \mathrm{rpm}$ for $10 \mathrm{~min}$ Then the supernatant was transferred into a pearshaped flask and added $20 \mathrm{ml}$ of acetone to the sediment before the mixture was sonicated for $10 \mathrm{~min}$. The solution was centrifuged once again and the supernatant was added to same pear-shaped flask. The mixed solution was evaporated $40^{\circ} \mathrm{C}$ until near dryness. Afterwards, $5 \mathrm{ml}$ of dichloromethane was added, homogenized by vortexing and transferred into a test tube. The step of addition of dichloromethane was repeated three times and the combined dichloromethane was dried at $40^{\circ} \mathrm{C}$. The residue was reconstituted with $1 \mathrm{ml}$ of $50 \%$ methanol in di-natrium hydrogen phosphate solution $(6 \mathrm{~g} / 1000 \mathrm{ml})$ and mixed properly by vortexing. N-hexane $(2 \mathrm{ml})$ was added into the test tube for defeating and vortexing before being removed. The remaining solution was filtered through the filter of $0.2 \mu \mathrm{m}$ or not more than $0.45 \mu \mathrm{m}$, and was ready for injection into HPLC system.

\section{Method Validation}

The method was validated in-house according to EMEA- notice to applicant and guidelineveterinary medical products (vol-8)-, and Commission Decision (EEC) No. 657/2002. For the criteria specified for quantitative method, and the validation parameters were determined by spiking blank chicken meat at three levels $0.5,1,1.5 \mathrm{MRL}$. The measured parameters were Calibration Curve, Specificity, Repeatability, Accuracy, Response Linearity, Limit of Detection and Limit of Quantification.

\section{A. Linearity and Range}

linearity is the ability of a method to the analyte concentration within the given range.

Range is the interval between upper and lower levels of analyte that have been demonstrated to the determined with precision, accuracy \& linearity using method as described.

\section{B. Accuracy (\% Recovery)}

The accuracy of an analytical method measures the agreement between the value, which is either as a conventional true value or and accepted reference value and the value found (i.e accuracy is a measure of the exactness of $\&$ analytical method). Accuracy is measure as the percent of analyte recovered after spiking samples in a blank.

\section{Precision}

Precision is the measure of the degree of repeatability of an analyte method under normal operation and is normally expressed as relative standard deviation for a statistically significant number of samples.

There are two types of precisions

\section{Repeatability}

This is the closeness of agreement between mutually independent test results obtains with the same method on identical test materials in the same laboratory by the same operator using the same equipment within short intervals of time.

\section{Intermediate precision (ruggedness)}

Intermediate precision is also called as ruggedness. this method measures the repeatability of the results obtain with the same method, on the same sample, in the 
same laboratory, but conducted by different operators in different days.

\section{Specificity}

The specificity of an assay is the capability to differentiate similar organisms or analytes or the other interferences from the matrix elements that could have a positive or negative effects on the assay value.

\section{E. LOD \&LOQ}

LOD is the lowest concentration of an analyte in a sample that can be detected but not necessarily quantitated under the stated experimental conditions. It can be determined by preparing a solution that is expected to produce a response i.e about 3 to 10 times that base line noise.

The solution is injected three times, and the $s / n$ ratio for each injection is recorded. The concentration of the solution is considered and LOD if the $s / n$ ratio is between 3 to $10 \mathrm{LOQ}$ can be determined in the same manner but with and $\mathrm{s} / \mathrm{n}$ ratio of 10 to 20 .

$$
\begin{aligned}
& L O D=3 \times S D / \text { slope } \\
& L O Q=10 \times S D / \text { slope }
\end{aligned}
$$

\section{RESULTS AND DISCUSSION}

\section{Antimicrobial assay}

Zone of inhibition for standard and sample was calculated (See Table No. 1 \& Figure. No. 1, Figure No:2). Out of twenty samples taken, the chicken meat samples in Kukatpally, Mehdipatnam, Yakatpura, Khairtabad, Secundrabad, Amberpet showed zone of inhibition when compared with thestandard sulphamethoxazole. Hence it proved that the meat samples containing antibiotics(sulphonamides).

Thin Layer Chromatographic method Forthe determination of Sulphonamides

TLC was performed for the identification of the sulphamethazine and Sulphamethaxazole by comparing $\mathrm{Rf}$ value of samples with the standard but meat sample showing only Sulphamethaxazole (see Figure No.2).

\section{RP-HPLC Method For the determination of Sulphamethoxazole}

Several trails were done and the optimized conditions was achieved on KROMOSIL 100 C18, $5 \mu$ column, di sodium hydrogen phosphate: methanol $(75: 25)$ mobile phase in isocratic mode and the Run time was $10 \mathrm{~min}$, the Column temperature was $25^{\circ} \mathrm{C}$ , Injection volume was $20 \mu \mathrm{l}$,peak observed at $4.5 \mathrm{~min}$ using flow rate of $1 \mathrm{ml} / \mathrm{min}$ with UV detection at $266 \mathrm{~nm}$. The developed method was validated according to $\mathrm{ICH}$ guidelines.(See Figure No:3\&4)

\section{METHOD VALIDATION}

\section{A. Linearity and range}

Established by plotting the peak area of each active component against its associated concentrations. The concentration used for sulphamethoxazole ranged from $30 \mu \mathrm{g} / \mathrm{kg}$ to $150 \mu \mathrm{g} / \mathrm{kg}(0.5 \mathrm{MRL}-1.5 \mathrm{MRL})$, at five levels, according to the recommendation made by the Commission Decision No. 657/2002.

A statistic linear regression was performed. Acceptance criteria: $r^{2}>0.999$ (coefficient of correlation). correlation coefficient was found to be 0.9993 (see Table No.2, Figure No:6).

\section{B. Accuracy (\% Recovery)}

It was determined by recovery experiments using blank matrices. 18 aliquots of a blank material were spiked (six aliquots) at each of $0.5,1$ and $1.5 \times$ MRL the samples were analyzed and the sulfonamides concentration present in each sample was Calculated; using the equation. The percentage recovery of Sulphamethaxazole is from $71.05-74.24 \%$ these values are within the criteria \% Recovery $(R)=100 \times$ measured content $/$ spiked level.(See Table No:3)

\section{PRECISION}

\section{REPEATABILITY}

Three test samples were spiked at analyte levels, which encompass $0.5 x$ and $2 x$ the MRL. Then, 6 test portions of each level were taken, analyzed and the residue concentration of each test portion was determined. The relative standard deviations (RSDs) of the sulfonamides for six measurements at $50 \mu \mathrm{g}$ $\mathrm{kg}-1,100 \mu \mathrm{g} \mathrm{kg}-1$ and $150 \mu \mathrm{g} \mathrm{kg}-1$ were from $0.3-1.46 \%$. These values are within the criteria stipulated for residue analysis by the Commission Decision No. 657/2002: $\mathrm{RSD}<20 \%$ (see table No.4)RSD $=$ SD/MEAN $\times 100$ (See Table No:4).

\section{SPECIFICITY}

Specificity was study by analyzing blank samples and spiked samples at relevant concentration $(0.5,1,1.5 \times \mathrm{MRL})$ and checking any interferences in the region of interest.

Percent peak width wasfound to be $103.6 \%$.So, there were no interfering peak in blank, sample and standard at retention time of these analyte in this mode and the peak width of analyte is within $90-110 \%$ of standard width (see figureNo.7\&8).

\section{E. LOD\&LOQ}

LOD of Sulphamethaxazole was found to be $1.5443 \mu \mathrm{g} / \mathrm{kg}$. 
LOQ of sulphamethoxazole was found to be $4.6798 \mu \mathrm{g} / \mathrm{kg}$.

\section{Comparative Studies}

Out of ten samples, Sulphamethoxazole concentration was detected in meat samples of six different areas from Hyderabad. Yakatpura and Mehdhipatnam samples are having concentration of Sulphamethoxazole more than MRLs established by INDIA $(0.1 \mu \mathrm{g} / \mathrm{g})$. The samples from the Amberpet, Secunderabad and Kukatpally are having Sulphamethoxazole concentration within the maximum residual limits (see table No.5).

\section{CONCLUSION}

An attempt was made for the analysis of antibiotic residues in various chicken meat samples of different regions in Hyderabad by RP-HPLC method. The screening of 20chicken meat samples showed occurrence of antibiotic residues like sulphamethoxazolein six different areas of Hyderabad, whereas Mehdipatnam and Yakutpura regions showed antibiotic residues above MRL which causes serious health concerns 11 in humans who consumes chicken meat in that regions. The level of antibiotic consumption in these areas should be evaluated and this study provides a basis for the need of an investigation on antibiotic residues in various chicken meat samples. Hence various educational and awareness programs should be conducted on the proper use of antibiotics in poultry industry.

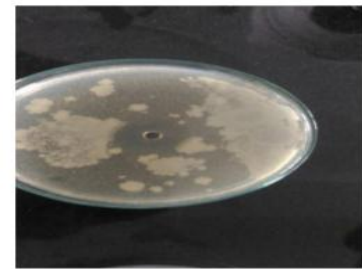

Fig. 1: Zone of inhibition of standard

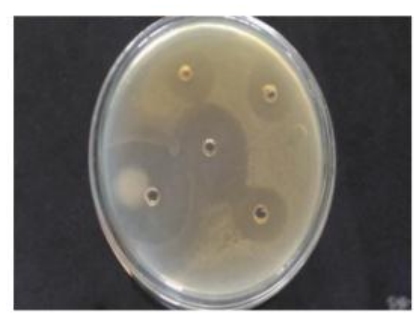

Fig. 2: Zone of inhibition of sample

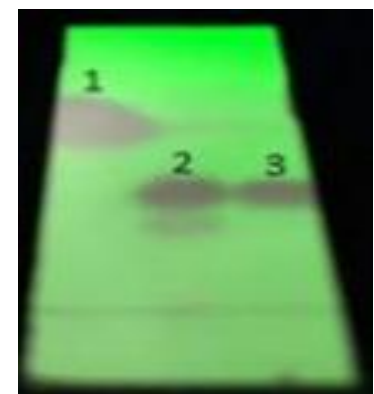

Fig. 3: TLC of standard and sample 


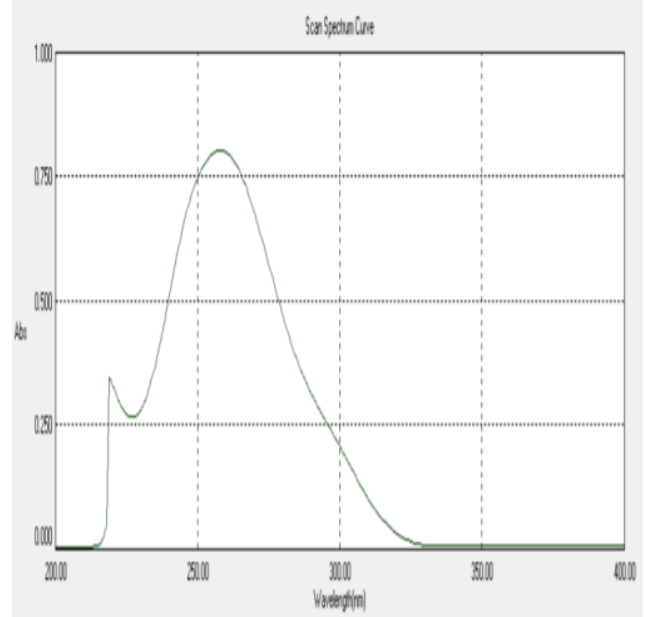

Fig. 4: UV spectra of sulphamethoxazole at $266 \mathrm{~nm}$

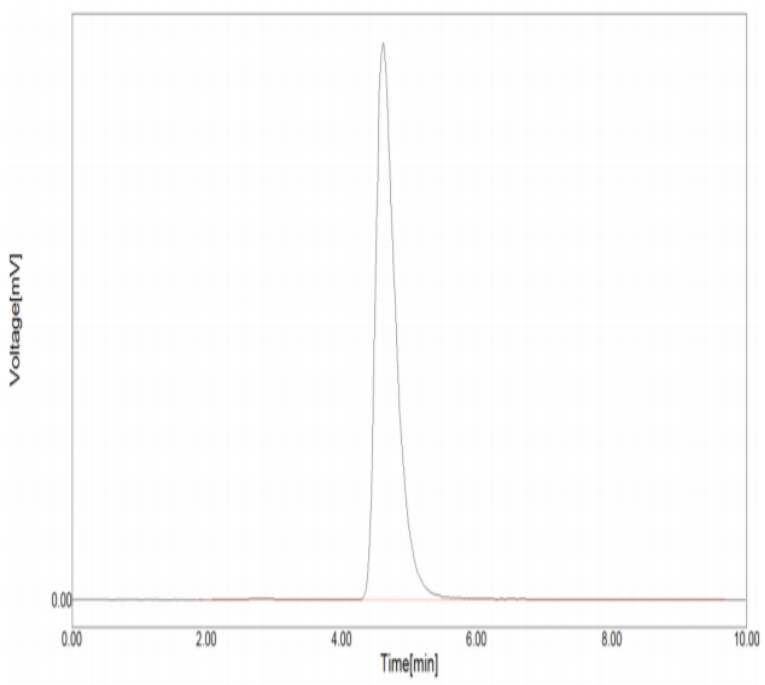

Fig. 5: Rt of sulphamethoxazole at $4.5 \mathrm{~min}$

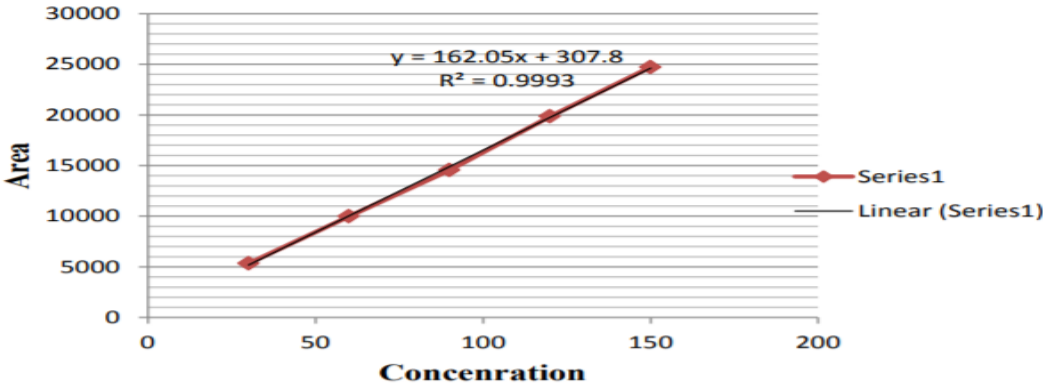

Fig. 6: Linearity of sulphamethoxazole 


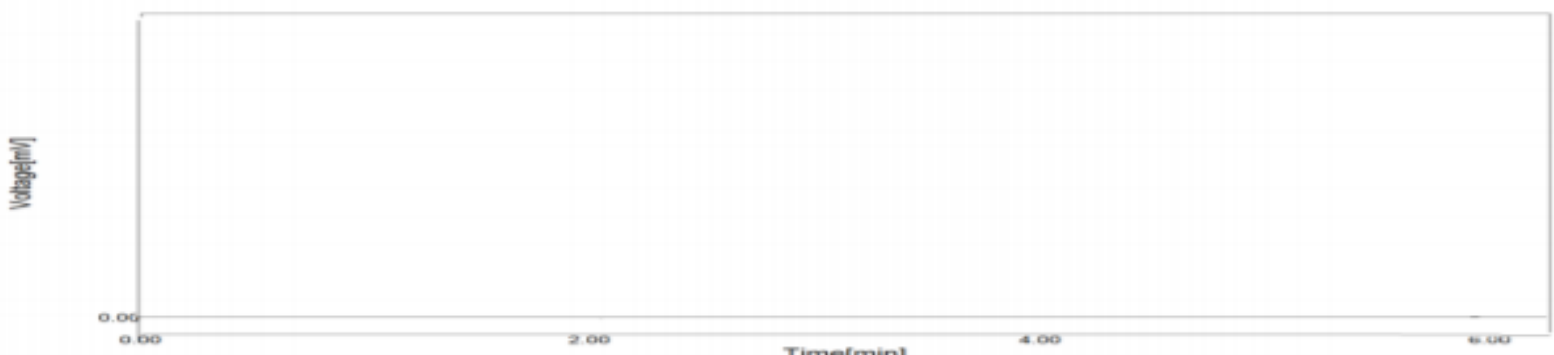

Fig. 7: chromatogram of blank

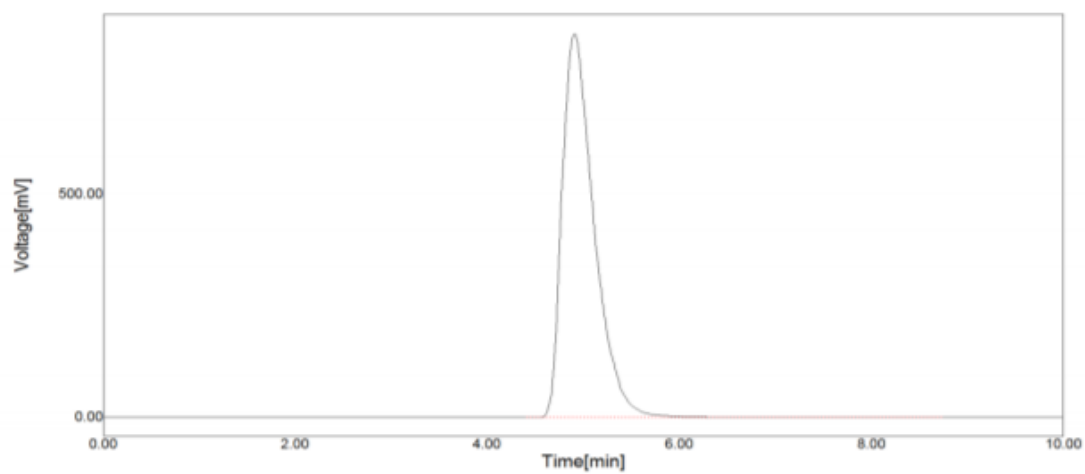

Fig. 8: Chromatogram of sample

Table 1: Microbial assay results

\begin{tabular}{|c|c|}
\hline concentration & Zone of inhibition \\
\hline 2 & 1.92 \\
\hline 4 & 2.11 \\
\hline 6 & 2.29 \\
\hline 8 & 2.48 \\
\hline 10 & 2.66 \\
\hline sample & 1.97 \\
\hline
\end{tabular}

Table 2: linearity data of sulphamethoxazole

\begin{tabular}{|c|c|}
\hline Concentration & Area \\
\hline 30 & 5346 \\
\hline 60 & 9989 \\
\hline 80 & 14550 \\
\hline 120 & 19855 \\
\hline 150 & 24720 \\
\hline
\end{tabular}

Table 3: Accuracy data of sulphamethoxazole

\begin{tabular}{|c|c|c|c|c|c|c|c|c|}
\hline \multicolumn{3}{|c|}{$50 \mu \mathrm{g} / \mathrm{ml}$} & \multicolumn{3}{|c|}{$100 \mu \mathrm{g} / \mathrm{m}$} & \multicolumn{3}{|c|}{$120 \mu \mathrm{g} / \mathrm{ml}$} \\
\hline Area & $\begin{array}{c}\text { Con. } \\
\text { obtained }\end{array}$ & $\%$ recovery & Area & $\begin{array}{c}\text { Con. } \\
\text { obtained }\end{array}$ & $\%$ recovery & Area & $\begin{array}{c}\text { Con. } \\
\text { obtained }\end{array}$ & $\%$ recovery \\
\hline 6375.6 & 37.45 & 74.91111 & 11497.2 & 36.03 & 72.07037 & 18797.8 & 38.045 & 76.09053 \\
\hline 6407.7 & 37.65 & 75.30741 & 11562 & 35.73 & 71.47037 & 19300 & 39.07 & 78.1572 \\
\hline 6164.8 & 36.15 & 72.30864 & 11775.4 & 35.39 & 70.78765 & 18462 & 37.35 & 74.70864 \\
\hline 6262 & 36.75 & 73.50864 & 11664.8 & 35.05 & 70.10494 & 17526.8 & 35.43 & 70.86008 \\
\hline 6326.8 & 37.15 & 74.30864 & 11875.4 & 35.7 & 70.4049 & 17429.6 & 35.23 & 70.46008 \\
\hline 6116.2 & 35.85 & 71.70864 & 11726.8 & 35.24 & 70.48765 & 18575.4 & 37.585 & 75.17531 \\
\hline \multicolumn{3}{|c|}{$\begin{array}{c}\text { \%mean recovery } \\
=(36.8 / 50) \times 100 \\
=73.6 \%\end{array}$} & \multicolumn{3}{|c|}{$\begin{array}{c}\% \text { mean recovery } \\
=(71.054 / 100) \times 100 \\
=71.05 \%\end{array}$} & \multicolumn{3}{|c|}{$\begin{array}{c}\% \text { mean recovery } \\
=(111.36 / 150) \times 100 \\
=74.24 \%\end{array}$} \\
\hline
\end{tabular}


Table 4: Repeatability data of sulphamethoxazole

\begin{tabular}{|c|c|c|c|c|c|}
\hline \multicolumn{2}{|c|}{ Con. At $\mathbf{5 0} \boldsymbol{\mu g} / \mathbf{m l}$} & \multicolumn{2}{c|}{ Con. At $\mathbf{1 0 0} \boldsymbol{\mu g} / \mathbf{m l}$} & \multicolumn{1}{c|}{ Con. At 150 $\boldsymbol{\mu g} / \mathbf{m l}$} \\
\hline Area & $\begin{array}{c}\text { Con. } \\
\text { Obtained }\end{array}$ & Area & $\begin{array}{c}\text { Con. } \\
\text { obtained }\end{array}$ & Area & $\begin{array}{c}\text { Con. } \\
\text { obtained }\end{array}$ \\
\hline 8375.6 & 49.8 & 16297.2 & 98.7 & 23797.8 & 148.8 \\
\hline 8407.7 & 50 & 16362 & 99.1 & 24300 & 148.1 \\
\hline 8164.8 & 48.5 & 16475.4 & 99.8 & 24462 & 149.1 \\
\hline 8262 & 49.1 & 16264.8 & 98.5 & 24526.8 & 149.5 \\
\hline 8326.8 & 49.5 & 16475.4 & 99.8 & 24429.6 & 148.9 \\
\hline 8116.2 & 48.2 & 16426.8 & 99.5 & 24575.4 & 149.8 \\
\hline \multicolumn{2}{|c|}{ Avg $=49.1$} & \multicolumn{2}{|c|}{ Avg $=99.23333$} & \multicolumn{2}{c|}{ AVG $=149.0$} \\
STD $=0.719$ & STD $=0.557$ & STD $=0.592$ \\
RSD $=1.465$ & RSD $=0.561$ & RSD $=0.397$ \\
\hline
\end{tabular}

Table 5: Comparative studies of meat sample concentrations in different areas

\begin{tabular}{|c|c|c|c|c|}
\hline S.No & Location & Area & $\begin{array}{c}\text { Sulphamethaxazole } \\
(\boldsymbol{\mu g} / \mathbf{g})\end{array}$ & MRL $(\boldsymbol{\mu g} / \mathbf{g})$ \\
\hline 1 & Amberpet & 329.5 & 0.037 & 0.1 \\
\hline 2 & Khairthabad & - & 0.042 & 0.1 \\
\hline 3 & Kukatpally & 343.72 & 0.067 & 0.1 \\
\hline 4 & Mehdipatnam & 355.96 & 0.202 & 0.1 \\
\hline 5 & Secunderabad & 316.18 & 0.015 & 0.1 \\
\hline 6 & Yakutpura & 398.8 & 0.182 & 0.1 \\
\hline
\end{tabular}

\section{REFERENCES}

1. Andrej Kirbis and Slovenia. Microbiological Screening Method for the detection of AminoglycosidesLactames, Macrolides, Tetracyclines and Quinolones in meat samples. Slov vet res. 2007;44(1/2): 8-11.

2. Bailac $S$, Ballesteros $O$, Jimenez-lazano E, Barron D, Navalon A and Barbosa J. Dtermination of Quinalones in chicken tissues by liquid chromatography with ultraviolet absorbance detection. Elsevier-Journal of Chromatography A. 2004;1029:145- 151.

3. Bhatti BM. International poultry congress and Exhibition. 2007;Nov. 9-10, Islamabad Pakistan.

4. Biswas AK, Rao GS, Kondaiah N, Anjaneyulu ASR and Malik JK. Simple multiresidue of trimethoprim and sulfonamides residues in buffalo meat by high performance liquid chromatography. J Agric Food Chem. 2007;55:8845-8850.

5. Biswas AK, Rao GS, Kondaiah N, Anjanehulu ASR, Mandiratta SK, Prasad $\mathrm{R}$ and Malik JK. A simple multi residue Method For Determination of Oxytetracycline and Chlortetracycline in Export Buffalo Meat by Hplc-photodiode Array Detector. Journal of food and Drug Analysis. 2007;21:1511-1520.

6. Blasco C, Masia A, Morillas FG AND Picó Y. Comparison of the effectiveness of recent extraction Procedures for antibiotic residues in bovine muscle tissues. J AOAC Int. 2011;94: 991-1003.
7. Capleton AC, Courage C, Rumsbya $P$, Holmesa P, Stutt E, Boxall ABA and Levy LS. Prioritising veterinary medicines according to their potential indirect human exposure and toxicity profile. Toxicology Letters. 2006;163:213-223.

8. Chen-HaoZhai and Yun Zou. Determination of Tetracyclines in Chicken by Solid phase Extraction and High-performance Liquid Chromatography, www.agilent.com/chem. 2008;59899735 EN.

9. Cheog, Hajeb CK, Jinap P and IsmailFitry MR. Sulphonamide determination in chicken meat products from Malaysia, internation Food Research Journal. 2010;17:885-892.

10. China Agriculture Ministry. Establishment of Maximum Residue Levels of Veterinary Medical Products in Foodstuffs of Animal Origin, PR China, Regulation No. 2002;235,

11. Chitescu CL, Nicolau Al, Csuma A and Moisoiu C. Simultaneous analysis of four sulfonamides in chicken muscle tissue by HPLC. Food AdditContam Part A Chem Anal Control Expo Risk Assess. 2011;28:1013-1020.

12. Cho HJ, Yi H, Cho SM, Lee DG AND Cho K. Single-step extraction followed by LC for determination of Fluoroquinolone drug residues in muscle, eggs, and milk. J Sep Sci. 2010;33: 1034-1043. 
13. Clark SB, Turnip seed SB, Madson MR, Hurlbut JA, Kuck LR and Sofos. Confirmation of Sulfamethazine, sulfathiazole, and sulfadimethoxine residues in condensed milk and softcheese products by liquid chromatography/tandem mass spectrometry. Journal of the Association of Official Analytical Chemists International. 2005;88:736-743.

14. Font $G$, Juan-García $A$ and Picó $Y$. Pressurized liquid extraction combined with capillary electrophoresis-mass spectrometry as an improved methodology for the determination of sulfonamide residues in meat. $J$ Chromatogr A. 2007;1159:233-241.

15. Franco DA, Webb $\mathrm{J}$ and Taylor CE. Antibiotic and sulphonamide residues in meat: Implication for human health. Journal of Food Protein. 1990;53:178185.

16. Fuh MRS and Chu SY. Quantitative determination of sulfonamide in meat by solid-phase extraction and capillary electrophoresis. Analytica Chimica Acta. 2003;499:215-221.

17. Gehring TA, Griffin B, Williams $R$, Geiseker C, Rushing LG. and Siitonen $\mathrm{PH}$. Multiresidue Sulfonamides determination in chicken meat products from Malaysia 891 International Food Research Journal. 2006;17:885-892.

18. Haagsma N, Dieleman B and Gortemaker BGM. A Rapid thin-layer chromatographic screening method for five sulfonamides in animal tissues. the veterinary quarterly. 1984;6(1):8-12.

19. H You, H Yu, Y Wu, Y Wang, C Liu and $S$ Chen. Simultaneous determination of 5 sulfonamides residues in beef by pressurized solvent extraction-high performance liquid chromatography. Chemistry. 2010;73:854-857.

20. Hajeb $P$, Jinap $S$, Ismail $A$, Fatimah $A B$, Jamilah $B$ and Abdul Rahim $M$. Assessment of mercury level in commonly consumed marine fishes in Malaysia. Food Control. 2009;20:79-84. 